\title{
O ELO ENTRE TUTOR E ALUNO NAS MODALIDADES EAD E HÍBRIDA: UM RELATO DE EXPERIÊNCIA A RESPEITO DA IMPORTÂNCIA DA AFETIVIDADE E INTERAÇÃO NO PROCESSO EDUCACIONAL
}

SÃO PAULO/SP MAIO/2018

\author{
Eliane Angeolini - UNICID - nika.angeolini@gmail.com \\ Lidiane Moutinho Neves - UNICID - lidiane.moutinho@gmail.com \\ Gabriel de Oliveira Alves - UNB - gabriel.o.a@gmail.com \\ Danilo Candido Bulgo - UNIFRAN - danilo.bulgo@gmail.com \\ Elizângela Leite Aziz - UNIFRAN - elizangela.aziz@gmail.com
}

Tipo: Relato de Experiência Inovadora (EI)

Categoria: Métodos e Tecnologias

Setor Educacional: EDUCAÇÃO SUPERIOR

RESUMO

O novo cenário educacional proporcionou evolução e novas possibilidades de ensino e aprendizagem. Dentre esse novo contexto, destaca-se o ensino a distância e o ensino híbrido, modalidades estas que propiciam aos alunos acesso ao conhecimento, trazendo alternativas na formação acadêmica e profissional dos indivíduos. Tal crescimento aumenta significativamente 0 número de vagas na educação superior, principalmente no setor privado, demandando novos modelos pedagógicos, visando à criação de ferramentas tecnológicas e a inserção de novos atores/funções no cenário educacional. Com essa expansão, surge a figura do tutor, um profissional essencial para o manejo e acompanhamento dos alunos. O presente trabalho teve por objetivo averiguar a importância do tutor na interação e afetividade nos processos de aprendizagem aos alunos, a fim de contribuir com a motivação para prosseguir com os estudos.

Palavras-chave: Palavras chaves: Educação a distância, Ensino Híbrido, Afetividade, Tutor. 


\section{INTRODUÇÃO}

É notória a transformação que vem ocorrendo no âmbito educacional, sendo estes resultados da evolução tecnológica e dos novos conceitos pedagógicos e sociais. A educação superior cresce a cada dia, aumentando assim os números de pessoas na busca por formação e especialização. Quando se fala em Educação à distância (EaD), verifica-se uma modalidade que ganhou força entre os séculos $\mathrm{XIX}$ e $\mathrm{XX}$, por meio de cursos realizados por correspondência e no século $X X$ o ensino mediado pelo rádio e pela televisão, até chegar no modelo atual com a chegada da informática, da internet e dos avanços da tecnologia, entre os séculos XX e o XXI, acrescentando maior velocidade e interatividade (AZEVEDO, 2012).

A EaD e o ensino híbrido se expandem e ganham novos adeptos, fazendo com que haja um volume grande de alunos matriculados em instituições de educação superior. Segundo Borges e Souza (2012, p. 2), a modalidade de ensino a distância permite ao aluno "promover a construção do conhecimento por meio de sua ação frente às situações didáticas planejadas e organizadas, contando com sua própria experiência, convivendo com a distância física".

Para acompanhar esse crescimento, novos profissionais foram surgindo para atender a respectiva demanda, entre eles nasce a figura que participa efetivamente do processo educacional dos educandos: o tutor. Este profissional assume um papel de grande importância no cenário virtual e presencial, necessitando aperfeiçoar uma gama de qualidades e competências em sua prática profissional, pois um elo deverá ser criado com o discente, com finalidade da mediação com clareza nas práticas constantes de apoio ao aluno.

Esse artigo tem por objetivo relatar a relevante participação do tutor no alcance de uma educação de qualidade nas modalidades $\mathrm{EaD}$ e híbrida, adequando à necessidade e evolução de cada aluno.

\section{OBJETIVO}

Relatar a importância do tutor no processo de ensino-aprendizagem aos alunos da modalidade de educação à distância e ensino híbrido, bem como a importância do elo criado entre tutor e aluno para menor evasão e continuação dos mesmos no curso.

\section{A importância do tutor, da comunicação e afetividade com o aluno contemporâneo}


A referida pesquisa foi idealizada a partir das experiências vivenciadas, as quais permitiram a construção de um relato de experiência.

Foi possível observar que o aluno da atualidade possui um perfil mais dinâmico, impulsivo, questionador, os quais possuem características essenciais para se inserir nos novos conceitos educacionais. A participação, autodisciplina, comunicação, autonomia e comprometimento são quesitos básicos para estudar na modalidade EaD e/ou híbrida.

O atual modelo pedagógico, que constitui o coração da universidade moderna, está se tornando obsoleto. No modelo industrial de produção em massa de estudantes, o professor é o transmissor. [...]. A aprendizagem baseada na transmissão pode ter sido apropriada para uma economia e uma geração anterior, mas cada vez mais ela está deixando de atender às necessidades de uma nova geração de estudantes que estão prestes a entrar na economia global do conhecimento (TAPSCOTT; WILLIAMS, 2010, p. 18-19).

Este novo modelo de educação superior, tanto para cursos $100 \%$ online, como para cursos híbridos, requerem por exigência do Ministério da Educação que os alunos sejam acompanhados e orientados por tutores presenciais e a distância.

Uma Instituição de Educação Superior, para ser credenciada na modalidade a distância, deve ter condições para oferta no que se refere a elaboração do PDI, Gestão Administrativa e Acadêmica, autoavaliação, experiência em EaD, equipe qualificada, professores e tutores titulados, instalações administrativas, serviços, recursos tecnológicos e biblioteca (BRASIL, 2007).

Percebe-se que o tutor presencial, quando bem preparado e orientado, atende às necessidades do aluno, reduz o nível de evasão da universidade, motiva, integra e resulta em melhores práticas de mediação pedagógica.

Instituições de Educação Superior que oferecem cursos a distância no modelo híbrido (blended learning) ou semipresencial, dispõem de professores tutores para orientação aos alunos.

O modelo híbrido (blended learning) ou semipresencial é um curso regular, que mescla momentos em que o aluno estuda os conteúdos e instruções usando recursos on-line, e outros em que o ensino ocorre em uma sala de aula, podendo interagir com outros alunos e com o professor (STAKER e HORN , 2012).

A partir de experiências vivenciadas, pode-se inferir que ao assumir a responsabilidade perante os alunos tanto nos ambientes virtuais (AVA) ou em salas de aula, o tutor necessita se manter ativo fomentando a participação do educando. Os ambientes 
virtuais são espaços ricos de recursos onde o aluno estuda, interage, participa e se relaciona com os demais alunos e o tutor. Os ambientes virtuais de aprendizagem (AVA's), oferecem aos alunos um espaço de oportunidades que agregam valores à sua formação acadêmica. Os fóruns de discussões são importantes neste processo, onde o tutor aponta questionamentos e instiga os alunos da sala virtual a participarem e trocarem conhecimentos sobre o proposto assunto.

Vale ressaltar que o tutor também media discussões dentro da modalidade híbrida, apontando assuntos pertinentes ao escopo estudo na sala de aula, estimulando assim o debate entre os alunos, assim por meio da mediação, os participantes possam ser mais participativos. Com o decorrer do tempo, os alunos vão assumindo a responsabilidade pela construção do seu aprendizado, sendo aptos a abordar novos assuntos e começam a somatizar e contribuir com experiências e conteúdos além daqueles fornecidos pelo curso.

Mattar (2012) reflete sobre o tutor a distância

O tutor é responsável pelo contato inicial com a turma, provocando a apresentação dos alunos e inclusive lida com os mais tímidos, que não se expõe com facilidade em um ambiente virtual; envia mensagens de agradecimento; fornece a eles feedback rápido; mantém um tom amigável. (MATTAR, 2012, p. 25).

O tutor então realiza a intermediação e operacionalização quanto ao andamento da disciplina, oferecendo incentivo e suporte aos alunos a realizarem atividades, esclarecendo dúvidas e mantendo a interação.

Segundo os Referenciais de Qualidade para Educação a Distância do MEC, o papel do tutor e sua função é:

\footnotetext{
O corpo de tutores desempenha papel de fundamental importância no processo educacional de cursos superiores a distância [...]. O tutor deve ser compreendido como um dos sujeitos que participa ativamente da prática pedagógica [...]. Sua principal atribuição é o esclarecimento de dúvidas através de fóruns de discussão pela Internet, pelo telefone, participação em videoconferências, entre outros, de acordo com o projeto pedagógico. $O$ tutor a distância tem também a responsabilidade de promover espaços de construção coletiva de conhecimento, selecionar material de apoio e sustentação teórica aos conteúdos e, frequentemente, faz parte de suas atribuições participar dos processos avaliativos de ensino-aprendizagem, junto com os docentes. (BRASIL, 2007, p. 21).
}

Ao se falar de afetividade e acolhimento, a aprendizagem e a afetividade se misturam na relação professor e aluno durante do processo de ensino-aprendizagem. 
Corroborando com a visão do Ministério da Educação, Santo (2008) aponta que:

[...] a afetividade exerce um papel fundamental nas correlações psicossomáticas básicas, além de influenciar, decisivamente, a percepção, a memória, o pensamento, a vontade e a ação, sendo assim, um componente essencial da harmonia e do equilíbrio da personalidade humana. (Santo, 2008, p. 4).

Neste sentido, Simonetto (2013) explica que, na educação a distância, não há como desmembrar as dimensões afetivas e cognitivas do funcionamento psicológico dos sujeitos, visto que a afetividade permeia a relação entre professor e aluno.

Acredita-se que ao se conectar e criar vínculo com os alunos na educação a distância e híbrida aumenta-se de maneira evidente a confiança dos alunos e o compromisso com os estudos, potencializando assim, a participação na aula e nos ambientes virtuais. Isso aumenta a qualidade do ensino no processo de aprendizagem e diminui a evasão dos alunos.

As transformações tecnológicas no contexto da educação têm sido rápidas, com isso, a necessidade de novas práticas discentes e docentes para mediação do conhecimento, não mais o velho paradigma do professor em sala com carteiras umas atrás das outras, sendo o docente o detentor do conhecimento. E com isso um grande desafio se coloca para os envolvidos nas práticas educativas, principalmente no processo de mediação na educação a distância, tendo em vista as novas relações e os novos papéis na comunicação envolvendo essa modalidade, que cresce exponencialmente.

Colaborando com esses indicativos, Moran (2013, p.8), argumenta que "a tecnologia nos atingiu como uma avalanche e envolve a todos". E com esse cenário, por meio da educação a distância, o aluno tem acesso à uma graduação de forma mais flexível, com a opção de gerenciar com autonomia o horário e local de estudo, conforme suas necessidades de trabalho ou por outras razões que o impediram de cursar o ensino presencial.

Devido a esse cenário, o tutor é o interlocutor entre plataforma de estudo e discente. 0 tutor se faz presente por meio de contatos em fóruns que promovam discussão de temas pertinentes ao seu curso, mensagens esclarecendo dúvidas aos alunos, mensagens de incentivos que motivam a produção do conhecimento e aprendizagem. Essa interação é o ponto de partida para efetiva produção do conhecimento, sendo essencial para crescimento e formação do discente da educação a distância. A qualidade da comunicação entre as figuras tutor/discente pode diminuir os efeitos da distância física existente, fazendo com que haja aproximação intelectual, formando cidadãos conscientes, preparados para um futuro profissional consistente e promissor. 


\section{CONSIDERAÇÕES FINAIS}

É inegável que os novos modelos educacionais fomentam a inserção de novos alunos nos cursos de educação superior. A demanda crescente traz uma mudança em conceitos tradicionalistas já instalados no cenário educacional. Assim, aborda-se as modalidades de ensino à distância e híbrida, sendo essas vertentes que fazem mudanças significativas na vida do indivíduo e no mundo, desenvolvendo novas perspectivas profissionais e sociais do mesmo. Os profissionais envolvidos nessa modalidade, em especial o tutor, é visto como um guia aos alunos, profissional este que trabalha de forma integrada, a fim de proporcionar interação, autonomia, autodisciplina e seja propagador de conhecimento por meio dos AVA's. Novas práticas pedagógicas, recursos tecnológicos, comunicação multidirecional abrem à educação uma gama de novos caminhos e novas oportunidades de acesso e democratização educacional.

\section{REFERÊNCIAS}

AZEVEDO, J. C. A. Os Primórdios da EAD no Ensino Superior Brasileiro. In: LITTO, F. E.; FORMIGA, M. (Org.). Educação a Distância. O estado da arte, 2. ed., v. 2. São Paulo: Person Education do Brasil, 2012.

BORGES, F. V. A.; SOUZA, E. R. Competências essenciais ao trabalho de tutoria: Estudo bibliográfico. In: SIMPÓSIO INTERNACIONAL DE EAD/ ENCONTRO DE PESQUISADORES EM EAD, 2012, São Carlos. Anais...São Carlos, São Paulo, 2012. p. $1-8$.

BRASIL. Ministério da Educação. Secretaria de Educação a distância. Referências de qualidade para a Educação Superior a distância. Brasília, ago. 2007. Disponível em: http://portal.mec.gov.br/seed/arquivos/pdf/legislacao/refead1.pdf . Acesso em: 06 de mai de 2018.

BRUNO, A. R.; LEMGRUBER, M. S. Dialética professor-tutor na educação on-line: o curso de Pedagogia UAB-UFJF em perspectiva. In: ENCONTRO NACIONAL SOBRE HIPERTEXTO, 3. 2009, Belo Horizonte, MG. Anais... Recife, Universidade Federal de Pernambuco, $2009 . \quad$ Disponível em: <https://www.ufpe.br/nehte/hipertexto2009/anais/a/a-dialetica-professor-tutor.pdf> Acessado em 05 de mai de 2018.

MATTAR, J. Tutoria e interação em educação a distância. Série Educação e Tecnologia. São Paulo: Cengage Learning, 2012. 
MORAN, J. M. O que é educação a distância. Acesso em: 17 mai. 2018. Disponível em: http://www2.eca.usp.br/moran/

SANTO, I. M. C. E. Educação a distância: Um estudo de caso sobre afetividade. CONGRESSO ABED, 2008, São Paulo. Anais eletrônicos... São Paulo: instituição, 2008. P. inicial e final.

SIMONETTO, K. C. C. Afetividade na educação a distância sob o olhar de alunos de pós graduação. Dissertação (Mestrado em Educação) Universidade do Oeste Paulista, SP, 2013.

TAKER, H.; HORN, M. B. Classifying K-12 blended learning. Mountain View, CA: Innosight Institute, Inc. 2012. Disponível em: . Acesso em: 15 abr. 2018.

TAPSCOTT, D.; WILLIAMS, A. D. Innovating the 21st-Century University: It's Time! Educause Review,January/February 17-29, 2010. Disponível em: . Acesso em: 15 abr. 2018. 